\title{
A dizziness questionnaire is helpful when assessing patients with dizziness in telephone consultations during the COVID-19 pandemic
}

\author{
Anna Kaleva ${ }^{1}$, Laura Leach $^{2}$, F. Fahmy ${ }^{3}$, Lucy Truman ${ }^{4}$, and Marcos Martinez Del Pero ${ }^{5}$ \\ ${ }^{1}$ Luton \& Dunstable NHS Trust \\ ${ }^{2}$ Department of Otorhinolaryngology, Peterborough City Hospital, North West Anglia NHS \\ Foundation Trust, UK \\ ${ }^{3}$ West Suffolk \& Addenbrooke's Hospitals \\ ${ }^{4}$ Addenbrooke's Hospital \\ ${ }^{5}$ Cambridge Teaching Hospitals
}

November 9, 2020

\begin{abstract}
No abstract as per guidelines. Key Points instead. Key points * The Roland Dizziness Questionnaire (RDQ) helped clinicians make a diagnosis in patients with dizziness during a telephone consultations * Use of the RDQ reduced the need for additional investigations and telephone follow-up * Use of the RDQ does not significantly reduce the need for face-to-face appointments

* Both patients and clinicians found the RDQ a useful addition to the assessment
\end{abstract}

A dizziness questionnaire is helpful when assessing patients with dizziness in telephone consultations during the COVID-19 pandemic

Running Title: Dizziness Questionnaire Paper

Word Count: 1473

\section{Key points}

- The Roland Dizziness Questionnaire (RDQ) helped clinicians make a diagnosis in patients with dizziness during a telephone consultations

- Use of the RDQ reduced the need for additional investigations and telephone follow-up

- Use of the RDQ does not significantly reduce the need for face-to-face appointments

- Both patients and clinicians found the RDQ a useful addition to the assessment

\section{Introduction}

On March $20^{\text {th }} 2020$, ENT UK recommended to its members that all routine clinics should be cancelled, and telephone review should be the first approach for all outpatients who do not need urgent treatment(1). Our ear, nose and throat (ENT) department sought to reduce delays and distress to patients by offering telephone assessments for suitable patients. Evidence supports making dizziness diagnoses from the medical history (2) alone, making telephone clinics appropriate.

We investigated whether a questionnaire would facilitate assessment and diagnosis of vestibular disorders over the telephone. Other studies have used questionnaires to enable diagnosis in patients complaining of dizziness, but most have focused on a single diagnosis e.g. BPPV (3) or disease severity(4). We selected a dizziness questionnaire described by Roland et al add ref because it was short, had been validated by its 
developers and was able to differentiate peripheral vestibular pathology from other causes of dizziness(5). Such a distinction could enable clinicians to decide whether patients need further investigations, a face-toface appointment, or referral to another specialty. This has the potential to reduce the number of visits to the hospital for each patient.

The primary objectives of this study were to assess whether use of the Roland (5) dizziness questionnaire (RDQ): facilitated diagnosis; reduced the number of investigations and face-to-face appointments; and increased discharges. Secondarily, clinicians and patients were asked to rate the questionnaire's helpfulness.

\section{Methods}

Ethical Considerations: The Research Operational Committee (ROC) at West Suffolk Hospital approved our project proposal for a randomised prospective study titled 'Utility of A Dizziness Questionnaire in ENT Balance Assessments in Times of COVID-19'.

Participants: All 115 patients awaiting a first balance assessment were included in the study. Patients were randomly assigned to study and control groups. 57 patients received a questionnaire (questionnaire group $(\mathrm{QG})$ ) and 58 patients did not (non-questionnaire group (NQG). The QG patients received a letter in the post asking them to complete the questionnaire and return it using a pre-stamped and addressed envelope, and explaining that this implied consent to participate. If returned in time, the clinician conducting the telephone consultation would read the RDQ before the consultation. The NQG group did not receive anything by post.

All telephone consultations were timed, and at the end of each consultation the clinician completed a survey. Any QG patients who did not return a completed questionnaire were excluded from analysis. Any patients for which the clinician did not complete the survey were also excluded.

Analysis: The CONSORT reporting guideline was used in preparation of this manuscript. The results were analysed using Microsoft Excel. The response rate (returned completed questionnaires) in the QG was 70\%, so the sample was considered representative. As the results constituted categorical data with a small sample size, Fisher's exact test was used to assess for a statistical difference between the two groups. A p-value of $<0.05$ was considered significant.

\section{Results}

115 patients were randomised, 57 to receive a questionnaire (questionnaire group, QG) and 58 to not receive a questionnaire (non-questionnaire group NQG) (See Figure 1). . The age range of patients was $13-95$ years with a mean age of 59 years. All patients were contacted and offered a telephone consultation for their balance complaint. Some patients were not contactable or declined the consultation as their problem had resolved. In the QG 40 of 57 patients completed and returned the questionnaire in the envelopes provided, giving a response rate of $70 \%$. Five of these patients' questionnaires arrived after their appointment, but since completion likely affected their ability to articulate their symptoms, they were included in the study. Thirtyfive of $57(61 \%)$ patients in the QG and 47/58 (81\%) patients in the NQG were included in the analysisFiftyseven patients of $82(70 \%)$ of the patients were female. Five clinicians conducted the consultations, three consultants and two specialist registrars. Fifty-two of 85 (61\%) patients had their consultation with an ENT consultant and $33 / 85(39 \%)$ with a specialty registrar. In the QG $22 / 38(51 \%)$ were seen by a consultant. In the NQG 30/47 (64\%) patients were seen by a consultant. The mean duration of telephone consultations was 13 minutes (range 3 -31 minutes) with no difference between the two groups $(\mathrm{p}=1)$. 


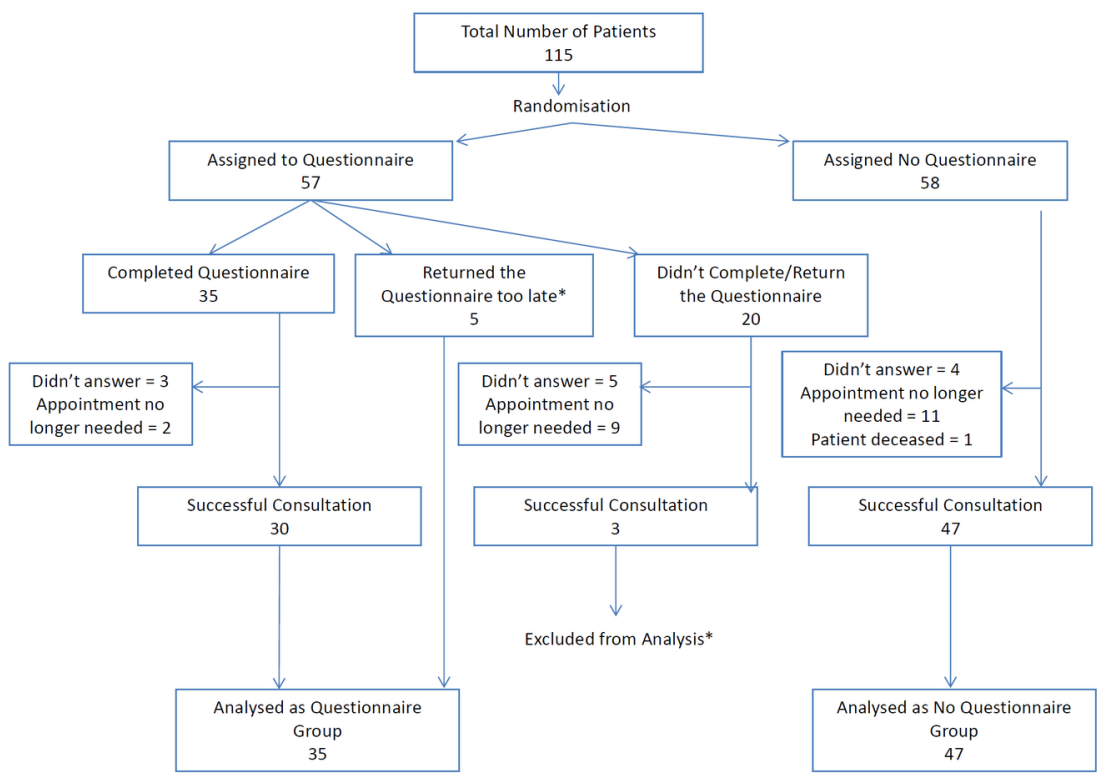

Figure 1. Consort Diagram

In the QG the likelihood that the clinician would make a diagnosis (77\%) was higher than in the NQG $(57 \%)$ but this did not reach statistical significance, $\mathrm{p}=0.0555$ (Table 1). The two most common diagnoses were Benign Paroxysmal Positional Vertigo (BPPV) 18/85 (21\%) and Vestibular Migraine 16/85 (20\%) (Figure 2 ). There was no significant difference in the distribution of diagnoses made in the two groups. Clinicians requested additional investigations, such as MRI scans, for 9/35 (26\%) of patients in the QG, compared to $34 / 47(72 \%)$ patients in the NQG, and this difference was statistically significant $\mathrm{p}=0.0409$. A greater proportion of QG patients were referred for vestibular physiotherapy 6/35 (17\%), than in the NQG 6/47 (13\%). After the initial telephone consultation, 18/35 (51\%) of QG patients were discharged compared to $19 / 47(40 \%)$ in the NQG. There were significantly fewer telephone follow-up consultations requested in the QG, 6/35 (17\%), compared to the NQG 20/47 (43\%), $\mathrm{p}=0.0173$. 


\begin{tabular}{|c|c|c|c|}
\hline 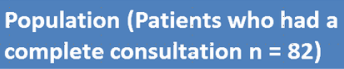 & $\begin{array}{l}\text { Questionnaire group } \\
(n=35)\end{array}$ & $\begin{array}{l}\text { No Questionnaire Group } \\
(n=47)\end{array}$ & $\begin{array}{l}\text { P-value (if } \\
\text { available) }\end{array}$ \\
\hline $\begin{array}{l}\text { Age Range }=13-95 \text { years } \\
\text { Age Mean }=59 \\
\text { Age Median }=62\end{array}$ & $\begin{array}{l}13-83 \text { years } \\
58 \\
58\end{array}$ & $\begin{array}{l}25-95 \text { years } \\
60 \\
68\end{array}$ & \\
\hline Female $=57(70 \%)$ & $23(66 \%)$ & $34(73 \%)$ & 0.629 \\
\hline $\begin{array}{l}\text { Duration of Consultation (mins) } \\
\text { Mean }=13 \\
\text { Median }=14\end{array}$ & $\begin{array}{l}13 \\
14\end{array}$ & $\begin{array}{l}13 \\
13\end{array}$ & 1 \\
\hline $\begin{array}{l}\text { Able to make a Diagnosis over } \\
\text { Telephone } \%=66 \%\end{array}$ & $27(77 \%)$ & $27(57 \%)$ & 0.0986 \\
\hline $\begin{array}{l}\text { Patient required an additional } \\
\text { face-to-face appointment }=23 \%\end{array}$ & $11(31 \%)$ & $8(17 \%)$ & 0.1855 \\
\hline $\begin{array}{l}\text { Patients required additional } \\
\text { investigations }=39 \%\end{array}$ & $9(26 \%)^{*}$ & $34(72 \%)^{*}$ & $0.0409^{*}$ \\
\hline $\begin{array}{l}\text { Patients were referred for } \\
\text { vestibular physiotherapy }=15 \%\end{array}$ & $6(17 \%)$ & $6(13 \%)$ & 0.7536 \\
\hline $\begin{array}{l}\text { Patients discharged after the } \\
\text { telephone consultation }=45 \%\end{array}$ & $18(51 \%)$ & $19(40 \%)$ & 0.3736 \\
\hline $\begin{array}{l}\text { Patients required additional } \\
\text { telephone follow-up = } 32 \%\end{array}$ & $6(17 \%)^{*}$ & $20(43 \%)^{*}$ & $0.0173^{*}$ \\
\hline *Statistically significant & & & \\
\hline
\end{tabular}

Table1. Telephone consultation outcomes

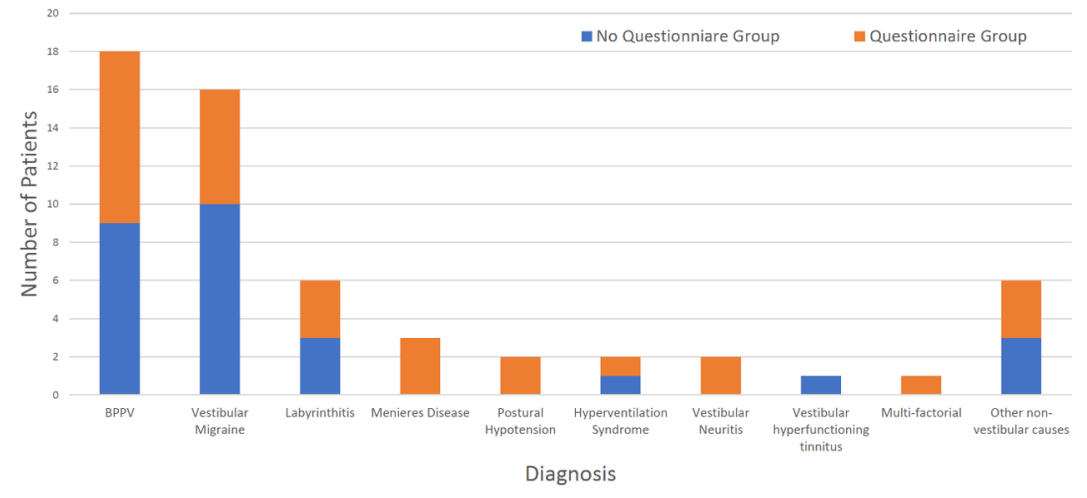

Figure 2. Diagnoses made

Across both groups, specialty registrars were significantly more likely to refer patients for vestibular physiotherapy, in $9 / 33(27 \%)$ cases vs $3 / 52(6 \%)$ of cases for consultants $(\mathrm{p}=0.0091)$. Consultants were significantly less likely to request any investigations for patients in the QG 2/20 (10\%) versus 14/30 (47\%) in the NQG $(\mathrm{p}=0.0055)$. No differences in outcomes were observed in either group between specialty registrars and consultants when it came to making a diagnosis, requesting additional face-to-face appointments, discharging patients and requesting telephone follow-up.

Sixteen patients who received and returned a completed questionnaire 16/35 (46\%) found the questionnaire a positive addition to their consultation, $3 / 35(9 \%)$ did not find it a positive addition and 16/35 (46\%) were unsure. The clinicians found the questionnaire helped the consultation $24 / 35(69 \%)$ of the time and thought that in $22 / 35(63 \%)$ of cases, they would have found the questionnaire helpful even in a pre-COVID19, face-to-face consultation. 


\section{Discussion}

The COVID-19 pandemic presents an opportunity to explore new ways to care for patients. Across the NHS, clinicians have had to adapt to reduced capacity, infection control and social distancing measures. Increasingly, virtual clinics are being introduced in secondary care. Studies have shown that diagnosis of peripheral vestibular pathology e.g. BPPV, made by telephone interview, compares favourably with diagnoses made by neuro-otologists in face-to-face clinics(6). Our study investigated whether telephone consultations for patients with dizziness had different outcomes when a diagnostic questionnaire was used. The findings suggest the questionnaire helped clinicians make a diagnosis, reduced the need for additional investigations and reduced telephone follow-up.

A number of questionnaires have been used in the management of dizziness such as the dizziness handicap inventory (DHI)(7) and the University of California, Los Angeles Dizziness Questionnaire (UCLA-DQ)(8). The results described above comprise the first report to specifically investigate the usefulness of a questionnaire in telephone consultations. These results show that using the Roland dizziness questionnaire (RDQ) as an adjunct to telephone consultations reduced the need for patients to come into hospital for face-toface consultations and reduced the number of investigations ordered and reduced the number of telephone follow-up appointments. The initial telephone consultation freed up ENT outpatient capacity for face-to-face consultations for conditions that need visual assessment, such as hoarseness or suspected cholesteatoma.

Our findings do not suggest that the questionnaire changes the rate of requests for further face-to-face ENT assessments. This may be because conditions such as Benign Paroxysmal Positional Vertigo (BPPV) require face-to-face diagnosis and treatment (Dix-Hallpike and Epley manoeuvres respectively) or perhaps patients with hearing loss struggle with telephone consultations. In the future treatments for conditions such as BPPV could potentially be delivered by tele-medicine e.g. by developing devices such as a cell phone balance trainer(9).

Other studies have described the patient perceptions of telemedicine in ENT practice during the COVID19 pandemic(10). We did not include a formal assessment of patient perception and satisfaction with the telephone consultation in our study. But we did ask both patients and clinicians about usefulness of the questionnaire. Telemedicine has been adopted out of necessity during the COVID-19 pandemic, but 46\% of patients found the questionnaire useful, suggesting growing acceptance of this 'new normal'. In an even greater proportion of consultations (69\%), clinicians found the questionnaire helpful - showing the usefulness of this questionnaire clinically.

\section{Conflict of interests}

The authors declare that they have no conflict of interest.

1. N. Kumar CH, P Tostevin and A Swift. ENT UK Covid - 19 letter to members, Friday 20 March. 2020.

2. Welgampola MS, Bradshaw AP, Halmagyi GM. Assessment of the Vestibular System: History and Physical Examination. Adv Otorhinolaryngol. 2019;82:1-11.

3. Kim HJ, Song JM, Zhong L, Yang X, Kim JS. Questionnaire-based diagnosis of benign paroxysmal positional vertigo. Neurology. 2020;94(9):e942-e9.

4. Yagi C, Morita Y, Kitazawa M, Nonomura Y, Yamagishi T, Ohshima S, et al. A Validated Questionnaire to Assess the Severity of Persistent Postural-Perceptual Dizziness (PPPD): The Niigata PPPD Questionnaire (NPQ). Otol Neurotol. 2019;40(7):e747-e52.

5. Roland LT, Kallogjeri D, Sinks BC, Rauch SD, Shepard NT, White JA, et al. Utility of an Abbreviated Dizziness Questionnaire to Differentiate Between Causes of Vertigo and Guide Appropriate Referral: A Multicenter Prospective Blinded Study. Otol Neurotol. 2015;36(10):1687-94.

6. von Brevern M, Radtke A, Lezius F, Feldmann M, Ziese T, Lempert T, et al. Epidemiology of benign paroxysmal positional vertigo: a population based study. J Neurol Neurosurg Psychiatry. 2007;78(7):710-5. 
7. Jacobson GP, Newman CW. The development of the Dizziness Handicap Inventory. Arch Otolaryngol Head Neck Surg. 1990;116(4):424-7.

8. Honrubia V, Bell TS, Harris MR, Baloh RW, Fisher LM. Quantitative evaluation of dizziness characteristics and impact on quality of life. Am J Otol. 1996;17(4):595-602.

9. Lee BC, Kim J, Chen S, Sienko KH. Cell phone based balance trainer. J Neuroeng Rehabil. 2012;9:10.

10. Triantafillou V, Layfield E, Prasad A, Deng J, Shanti RM, Newman JG, et al. Patient Perceptions of Head and Neck Ambulatory Telemedicine Visits: A Qualitative Study. Otolaryngol Head Neck Surg. 2020:194599820943523.

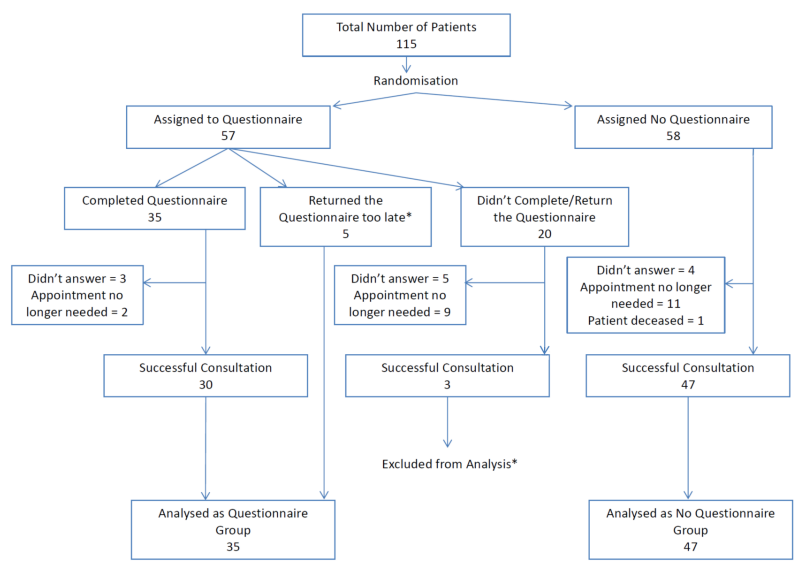

Figure 1. CONSORT Diagram

\begin{tabular}{|c|c|c|c|}
\hline $\begin{array}{l}\text { Population (Patients who had a } \\
\text { complete consultation } n=82 \text { ) }\end{array}$ & $\begin{array}{l}\text { Questionnaire group } \\
(n=35)\end{array}$ & $\begin{array}{l}\text { No Questionnaire Group } \\
(n=47)\end{array}$ & $\begin{array}{l}\text { P-value (if } \\
\text { available) }\end{array}$ \\
\hline $\begin{array}{l}\text { Age Range }=13-95 \text { years } \\
\text { Age Mean }=59 \\
\text { Age Median }=62\end{array}$ & $\begin{array}{l}13-83 \text { years } \\
58 \\
58\end{array}$ & $\begin{array}{l}25-95 \text { years } \\
60 \\
68\end{array}$ & \\
\hline Female $=57(70 \%)$ & $23(66 \%)$ & $34(73 \%)$ & 0.629 \\
\hline $\begin{array}{l}\text { Duration of Consultation (mins) } \\
\text { Mean }=13 \\
\text { Median }=14\end{array}$ & $\begin{array}{l}13 \\
14\end{array}$ & $\begin{array}{l}13 \\
13\end{array}$ & 1 \\
\hline $\begin{array}{l}\text { Able to make a Diagnosis over } \\
\text { Telephone } \%=66 \%\end{array}$ & $27(77 \%)$ & $27(57 \%)$ & 0.0986 \\
\hline $\begin{array}{l}\text { Patient required an additional } \\
\text { face-to-face appointment }=23 \%\end{array}$ & $11(31 \%)$ & $8(17 \%)$ & 0.1855 \\
\hline $\begin{array}{l}\text { Patients required additional } \\
\text { investigations }=39 \%\end{array}$ & $9(26 \%)^{*}$ & $34(72 \%)^{*}$ & $0.0409^{*}$ \\
\hline $\begin{array}{l}\text { Patients were referred for } \\
\text { vestibular physiotherapy }=15 \%\end{array}$ & $6(17 \%)$ & $6(13 \%)$ & 0.7536 \\
\hline $\begin{array}{l}\text { Patients discharged after the } \\
\text { telephone consultation }=45 \%\end{array}$ & $18(51 \%)$ & $19(40 \%)$ & 0.3736 \\
\hline $\begin{array}{l}\text { Patients required additional } \\
\text { telephone follow-up }=32 \%\end{array}$ & $6(17 \%)^{*}$ & $20(43 \%)^{*}$ & $0.0173^{*}$ \\
\hline
\end{tabular}

*Statistically significant 


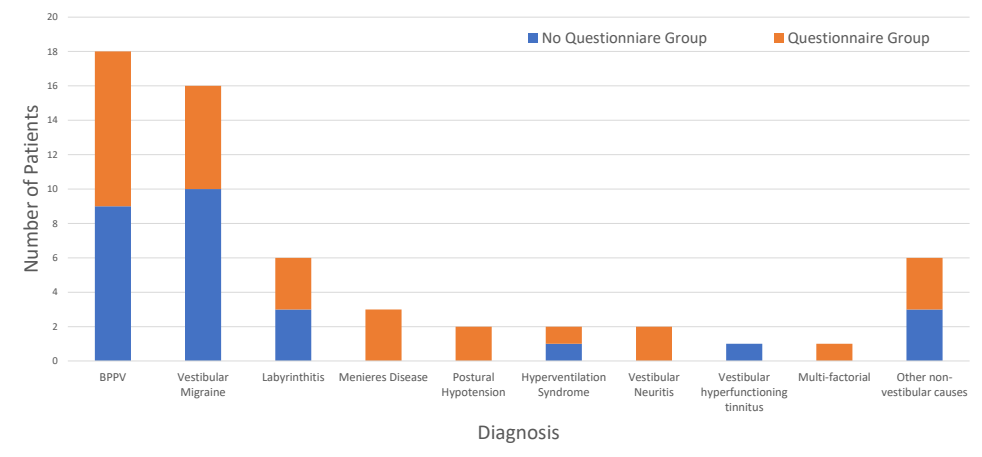

